\title{
Unveiling the realities of marrying too young: implications of child marriage on sexual and reproductive health of girls and infant survival in Sub-Sahara Africa.
}

\author{
Emmanuel O. Olamijuwon ${ }^{1,2}$, Vesper H. Chisumpa ${ }^{1,3}$ \& Joshua O. Akinyemi ${ }^{1,4}$ \\ 1Demography and Population Studies, Schools of Public Health and Social Sciences, \\ Faculties of Health Sciences and Humanities, \\ University of the Witwatersrand, Johannesburg, South Africa. \\ ${ }^{2}$ Institute for Health Measurement (IHM), Mbabane, Swaziland. \\ ${ }^{3}$ Department of Population Studies, University of Zambia, Lusaka, Zambia. \\ ${ }^{4}$ Department of Epidemiology and Medical Statistics, College of Medicine, University of Ibadan, \\ Ibadan, Nigeria
}

emmanuel@olamijuwon.com; emmanuel.olamijuwon@wits.ac.za

\begin{abstract}
Despite laws against child marriage, the practice remains widespread in sub-Sahara Africa (SSA), partly because of poverty, inequality, and cultural norms. We examined the levels of child marriage as well as its implications for the sexual and reproductive health of girls and infant survival in SSA. Data was drawn from the recent DHS of 18 countries in SSA. Results show that women who married earlier than I 8years were less likely to use a modern method of contraception [OR:0.92, Cl:0.869-0.982], more likely to experience sexual violence [OR:I.33, Cl:I.|88-I.487], had fewer antenatal visits [IRR:0.94, $\mathrm{Cl}: 0.926-0.950]$ and less likely to deliver at a health facility [OR:0.53, Cl:0.495-0.560]. They were also less likely to be assisted by a skilled birth attendant [OR:0.65, Cl:0.609-0.685] and their first births were less likely to survive infancy [HR:0.84, $\mathrm{Cl}: 0.8 \mid 4-0.869]$. These findings highlight the negative implications of child marriage and the need for heightened efforts to reduce its practice.
\end{abstract}

Keywords: child marriage, reproductive health, contraceptive use, sexual violence, infant survival.

\section{Introduction}

Despite laws against child marriage, a violation of child rights, the practice remains widespread, in part because of persistent poverty, gender inequality, protection and the need to reinforce family ties (Nour, 2009). Although many countries had passed laws changing the legal age of marriage to 18 years, enforcement of these laws and those requiring marriages to be registered remain weak as over 14 million marriages in sub-Saharan Africa (SSA) include girls under 18 years with over three-in-five girls married before age 18 years in many sub-Sahara Africa countries (Nour, 2009; Nour, 2006; Mathur, Greene, and Malhotra, 2003). The implications of child marriage on health and prospects are diverse as girls in this situation often end up embracing their new environment and prove their fertility to survive even when premature childbirth has been known to lead to a variety of health problems, including fistula (Nour, 2006). Girls with fistula are often abandoned by their husbands and ostracized by society (Nour,
2006). Other known implications of this form of marriage are poverty, increased risk of HIV/AIDS and other sexually transmitted infections, sexual and other forms of violence, high risk of death during childbirth and inability to continue schooling (Nour, 2006; Greene and Malhotra, 2003; Bruce and Clark, 2003).

Child marriage has enormous implications on the region's economic development as it impacts on the girl child's education, political and labour force participation thereby preventing significant progress towards achieving Sustainable Development Goals (Lee-Rife, et. al, 20/2). The implication of child marriage on the reproductive health of girls has been extensively explored in the Asian countries showing its detrimental effect, however, it has been sparsely explored in SSA. For instance, a multi-country study of the implications of child marriage in Bangladesh, India, Nepal, and Pakistan revealed that child marriage was significantly associated with poor fertility outcomes and lower contraceptive use early 
in marriage coupled with inadequate maternal health care use (Godha, Hotchkiss \& Gage, 2013). Their findings also suggest that child marriage was a significant predictor of antenatal visits in Bangladesh and Nepal (Godha, Hotchkiss \& Gage, 20I3). They also found that women that married as a child were significantly less likely to be assisted by a skilled health worker compared to those that married at 18 years or older (Godha, Hotchkiss \& Gage, 2013). Young women who had married before age 18 years in India were also significantly different from those that married later in relation to sexual and reproductive health outcomes (Santhya, et al., 20I0). For instance, delivery of first birth at a health facility was significantly lower among young women compared to those that married later than 18 years old (Santhya, et al., 20I0). Conversely, women who had married at age 18 years or older had a lower odd of experiencing sexual violence compared to those that married at younger ages (Santhya, et al., 20l0).

Consequently, marriage before age 18 years in India and particularly among youth from Rajasthan in India was shown to be significantly linked to a higher risk of intimate partner violence (Speizer and Pearson, 20I I). Their finding is also consistent with other previous studies where early marriage was shown to increase both women's risk of violence in the last 6 months and lifetime intimate partner violence (Rocca et al., 2009; Jejeebhoy and Cook, 1997).

A multi-country study of child marriage and its link to national rates of HIV, maternal health and Infant mortality in 97 countries showed that child marriage was associated with reduced rates of skilled birth attendant utilization but not significantly associated with modern contraceptive use (Raj and Boehmer, 2013). Using data from the 2009 United Nations reports, Raj and Boehmer, 20I3's findings suggest that a $10 \%$ increase in child marriages in a country is associated with a $3 \%$ increase in the country's infant mortality rate as well as a lower likelihood of being assisted by a skilled birth attendant. Similarly, Indian women who marry late were more likely to have better reproductive health than women who married at an early age (Prakash et al., 20I I).

Indeed, only a few studies in sub-Saharan Africa have explored the implications of child marriage, although descriptive rather than analytical, much remains to be explored particularly in relation to sexual and reproductive health as well as the high rate of infant mortality where about $75 \%$ of all under-five deaths occur within the first year of life (WHO, 2015; Raj \& Boehmer, 2013; Nour, 2009; Nour, 2006).
In this study, we, therefore, provide empirical evidence on the relationship of child marriage with sexual and reproductive health. We explore further its implications on the region's high infant mortality rate. Although child mothers are often not psychologically strong and are at risk of maternal mortality, if they survive, do they have the emotional and psychological ability to reduce the risk of infant mortality for their child too? Will family support for child marriage in the SSA region translate to better health for the off-spring? These and others are important questions we expect to provide answers to as we begin our analyses by unveiling the characteristics of current child brides in SSA as well as those of their partners.

A proper understanding of this association is essential for policy interventions towards reducing child marriages, high infant mortality and improving the health status of girls and women in SSA. Awareness of these relationships would also contribute substantially towards achieving the sustainable development goals.

\section{Data sources and methods \\ Research design and data}

This cross-sectional study uses pooled data from the recent (20I0-20I5) Demographic and Health Surveys (DHS) of 18 sub-Saharan African countries divided according to the regional classification of the African Union. Countries were included if the available data was collected between 2010 and 2015 and contains information on the experience of sexual violence. West Africa data was aggregated from data for Burkina Faso (20I0), Gambia (20/3), Nigeria (20/3) and Togo (20/3-I4). Data for Central Africa was aggregated from data for Cameroon (20II), Chad (20I5), Gabon (20I2) and the Republic of Congo (20/3-14). East African data was aggregated from data for Comoros (20/2), Kenya (20/4), Rwanda (20I4-I5), and Uganda (20II). Data for Southern African region was aggregated from data for Malawi (20I0), Mozambique (20II), Namibia (20।3), Zambia (20I3-14) and Zimbabwe (20I0-II).

\section{Study population and sample}

The study populations are girls less than 18 years, young women, between 20-24 years and first order births born within the last five years preceding the surveys. The study sample was, therefore, a weighted distribution of 34,257 girls under 18 years, 25,327 young women between ages 20-24 years and 17,303 first order births born within the last five years preceding the surveys. 
Figure I: Sample selection procedure

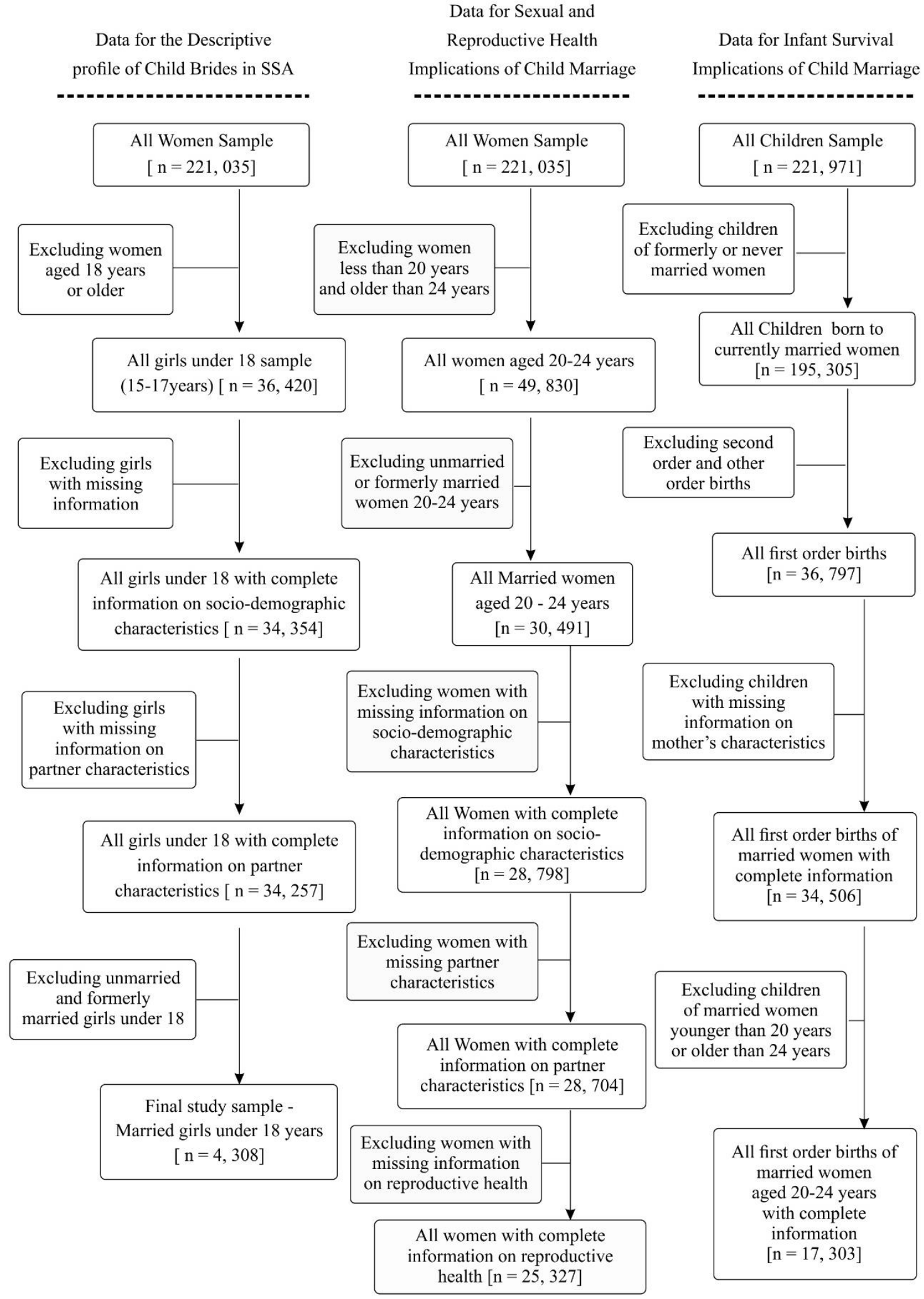

\section{Variable description}

The outcome variables in this study are reproductive health and infant survival. Modern contraceptive use, an experience of sexual violence, skilled birth attendance, the number of antenatal care visits and place of delivery were used to assess women's reproductive health. Use of a modern method of contraception was coded (I) for women who reported to be using a modern method and (0) for women using a traditional or not using any method at all. Experience of sexual violence was assessed from the question that asked if women had experienced any sexual violence from the husband or partner. Women that reported "Yes" were coded (I) while those who reported "No" were coded (0). Skilled birth attendance from the question that asked who 
assisted women during birth. Women that were assisted by doctors, nurses, midwives and auxiliary midwives were classified as "Yes" and coded (I) while other were coded (0) and classified "No." Similarly, the number of antenatal visits was assessed from the DHS question that asked for the number of times women visited antenatal care during the pregnancy of their first child. These responses were treated as a count variable starting from (0) - no visit to (29) times. Place of delivery was also assessed from the DHS question that asked for where the first birth was delivered. Women that delivered at a government or private health facility were classified as "health facility" and coded (I) while those who gave birth at home, church or other places were coded (0). Infant survival was defined as survival of a new-born during the first II months of life. Data on children's survival was analysed as time to event which was generated by a combination of children's current age for living children and age at death for children reported to be dead.

The main explanatory variable for this study is age at marriage which was dichotomized for comparison between the groups. Women who were married before 18 years were classified as 'child at marriage' and coded (I) while women who were 18 years or older at marriage were classified as 'adult at marriage' and coded (0).

Control variables included in the study are educational attainment, woman's employment status, partner employment status, place of residence, religious affiliation, household wealth and child sex. Educational attainment was assessed from the question that asked for a woman's highest level of education. Responses to these questions were coded (0) for women with no education, (I) for women with primary education and (2) for women with secondary or higher education. Employment status was also assessed from the question that asked if a woman is currently working or not. Women that reported to be working were coded (I) employed or (0) unemployed if they are not working. Partner characteristics were also assessed from the question that asked if currently or formerly married women's partners are working or not as well as their highest educational attainment. Women whose partners were not working are coded $(0)$ unemployed while those whose partners are working were coded (I). Similarly, women whose partner has no formal education were coded $(0)$ no education while those whose partner have primary were coded (I) and those with secondary education were coded (2). Religious affiliation was categorized and coded $(0)$ if a woman reported not to be affiliated with any religious group, (I) if she reported being a Christian, (2) if she reported being a Muslim and (3) if she's a member of other religious groups including traditional religions. Household wealth was assessed using an index that combined ownership of several key household assets and utilities. The index was divided into quartiles and subsequently reclassified as rich (2) if women reported being richer or richest, middle or average ( $I$ ) and poor (0) if they were poorer or poorest.

Data and variables for each country were checked to ensure that the categories are consistent before pooling.

\section{Analytical approach}

Responses to the standard DHS questions were managed, transformed and analyzed using Stata software version 14. Frequency and percentage distributions were used to explore the levels and patterns of child marriage across selected socioeconomic and partner characteristics across the regions of SSA. Binary logistic regression was applied to examine the association of child marriage with the place of delivery (first birth), skilled birth attendance (first birth), experience of sexual violence and modern contraceptive use (Long \& Freese, 2006). Due to the count nature of the number of antenatal care visit (first birth), a Poisson regression model was used to explore its relationship with child marriage. To also examine the relationship between child marriage and infant survival, a Cox-proportional hazard regression model was fitted. Interpretations of results were done using odds ratios (OR-for logistics regressions), incidence rate ratios (IRR-for Poisson regression), and hazard ratios (HR-for coxregression) with $H R / I R R / O R>I$ implying higher risk, $H R / I R R / O R<I$ implying lower risk and $H R / I R R / O R=I$ implying no risk difference. Observations were weighted to correct for sampling errors.

\section{Results}

Figure I below shows that about one-in-ten girls under 18 years of age in sub-Saharan Africa are already married with variations as high as almost I5\% in West and Central Africa to less than $5 \%$ in East Africa. 
Levels of Child marriage in sub-Saharan Africa and sub-regions

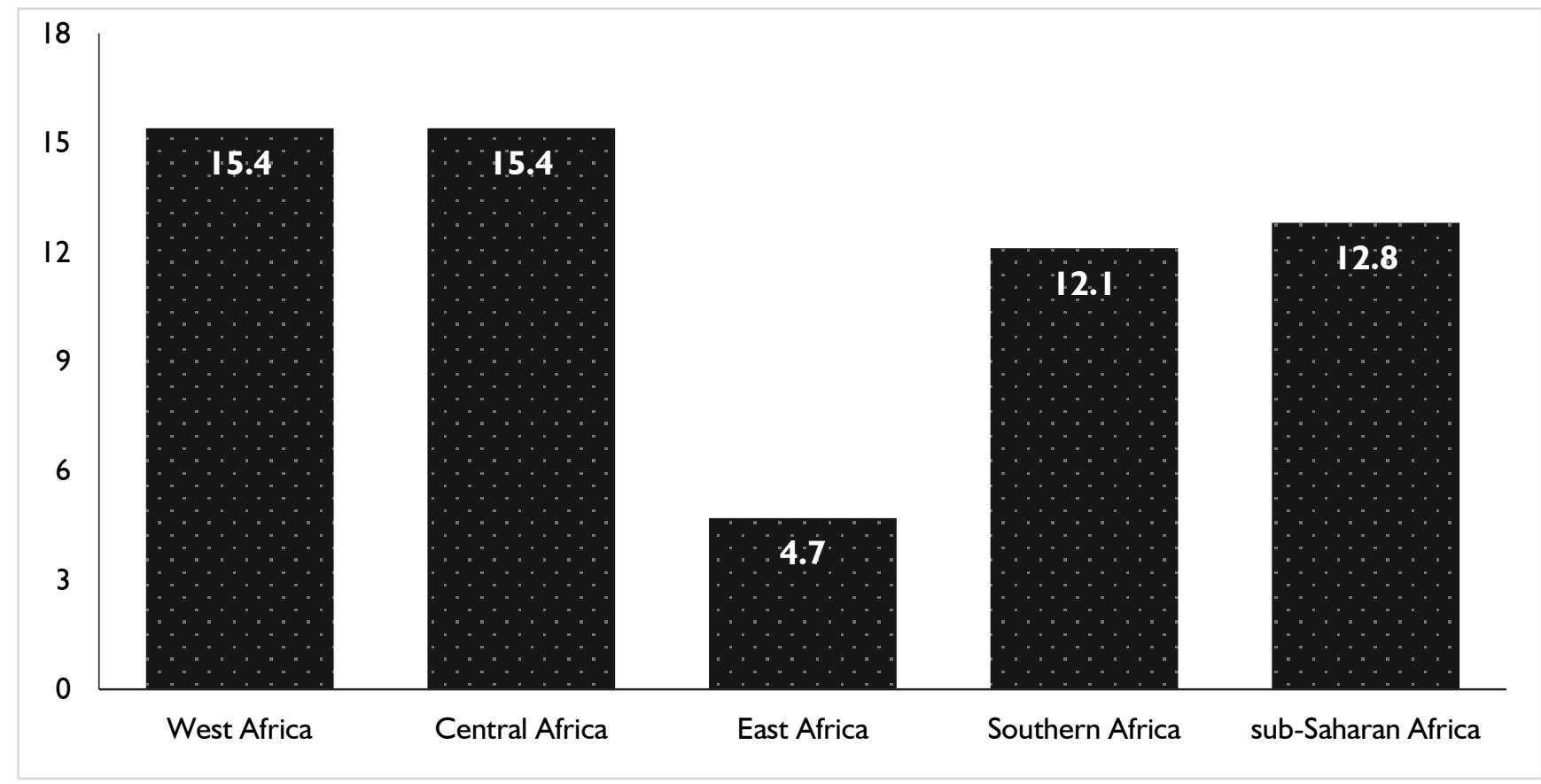

Profile of child brides in sub-Saharan

\section{Africa and sub-regions}

Table I below shows the profile of child brides in sub-Saharan Africa by selected socio-economic and demographic characteristics as well as partner characteristics. It is evident that majority of the married girls had their first sex at first union in subSaharan Africa (56\%), West Africa (82\%) and Central Africa $(63 \%)$ regions. Conversely, in East Africa $(65.7 \%)$ and in Southern Africa (85.6\%), majority of the girls had their first sex before first marriage. The majority (almost 59\%) of the married girls in subSaharan Africa have not given birth and a similar pattern could be observed across the regions. More than half of the married girls in West Africa (65\%) and East Africa $(51 \%)$ live in poor households. Similarly, the majority $(72 \%)$ of the married girls in West Africa have no formal education while more married girls in East Africa (64\%) and Central Africa $(73 \%)$ had primary education. Slightly above onequarter of the girls in Central (29\%) and East Africa
(26\%) also had at least secondary education. More than three-quarters of the girls in sub-Saharan Africa reside in the rural place of residence. A similar distribution was also observed in West Africa (84\%), and Southern Africa $(81 \%)$. More than half of the married girls in sub-Saharan Africa and sub-regions are currently unemployed. Exploring the pattern of child marriage by partner characteristics, it is evident that many of the married girls are married to men who are much older than them. For instance, $44 \%$ of the married girls in West Africa are married to men older by II + years while only about one- tenth of the girls in Southern Africa are married to men older by II or more years. Conversely, the majority of the girls are married to men who are currently employed while about one-fifth of the girls do not know their partner's employment status. Indications by partner's educational attainment show that about $65 \%$ of the girls in West Africa are married to men with no formal education while more than half are married to men with primary education in East Africa (53\%) and Southern Africa (54\%). 
Table I: Profile of child brides across selected socioeconomic and demographic characteristics in SSA, (DHS 2010-15)

\begin{tabular}{|c|c|c|c|c|c|}
\hline $\begin{array}{l}\text { Socio-Demographic } \\
\text { Characteristics }\end{array}$ & $\begin{array}{l}\text { West Africa } \\
(1,748)\end{array}$ & $\begin{array}{l}\text { Central } \\
\text { Africa } \\
(1,165)\end{array}$ & $\begin{array}{l}\text { East } \\
\text { Africa } \\
(250)\end{array}$ & $\begin{array}{l}\text { Southern } \\
\text { Africa } \\
\qquad(1,145)\end{array}$ & $\begin{array}{l}\text { sub-Sahara } \\
\text { Africa } \\
(4,308)\end{array}$ \\
\hline \multicolumn{6}{|l|}{ Sexual Experience } \\
\hline Never had Sex & 3.0 & 1.3 & 2.4 & 0.4 & 1.8 \\
\hline Ever had Sex & 14.8 & 35.6 & 65.7 & 85.6 & 42.2 \\
\hline At First Union & 82.2 & 63.2 & 31.9 & 14.0 & 56.0 \\
\hline \multicolumn{6}{|l|}{ Fertility Experience } \\
\hline Never Given Birth & 66.2 & 50.1 & 59.9 & 56.6 & 58.9 \\
\hline Given Birth & 33.8 & 49.9 & 40.1 & 43.4 & 41.1 \\
\hline \multicolumn{6}{|l|}{ Age at First Birth } \\
\hline Mean (Years) & 15.4 & 15.2 & 15.7 & 15.6 & 15.4 \\
\hline \multicolumn{6}{|l|}{ Wealth Status } \\
\hline Poor & 64.9 & 46.9 & 50.6 & 47.4 & 54.5 \\
\hline Average & 18.8 & 20.4 & 18.4 & 23.2 & 20.4 \\
\hline Rich & 16.3 & 32.7 & 31.0 & 29.4 & 25.1 \\
\hline \multicolumn{6}{|l|}{ Educational Attainment } \\
\hline No Education & 71.7 & 36.8 & 9.8 & 11.8 & 42.7 \\
\hline Primary Education & 15.9 & 34.3 & 63.7 & 72.8 & 38.8 \\
\hline Secondary Education & 12.4 & 28.9 & 26.5 & 15.5 & 18.5 \\
\hline \multicolumn{6}{|l|}{ Place of Residence } \\
\hline Urban & 15.5 & 29.8 & 28.5 & 18.6 & 20.9 \\
\hline Rural & 84.5 & 70.2 & 71.5 & 81.4 & 79.1 \\
\hline \multicolumn{6}{|l|}{ Employment Status } \\
\hline Unemployed & 60.0 & 61.5 & 54.7 & 68.9 & 62.5 \\
\hline Employed & 40.0 & 38.5 & 45.3 & 31.1 & 37.5 \\
\hline \multicolumn{6}{|l|}{ Partner Age Difference } \\
\hline Older Wife & 0.0 & 0.0 & 0.7 & 0.9 & 0.3 \\
\hline No Age Difference & 0.1 & 0.4 & 2.0 & 1.0 & 0.5 \\
\hline Younger by I-5 Years & 19.7 & 32.0 & 40.3 & 53.0 & 33.1 \\
\hline $\begin{array}{l}\text { Younger by 6-10 } \\
\text { Years }\end{array}$ & 36.3 & 34.6 & 34.7 & 34.9 & 35.4 \\
\hline $\begin{array}{l}\text { Younger by } 11+ \\
\text { Years }\end{array}$ & 43.9 & 33.0 & 22.4 & 10.3 & 30.8 \\
\hline \multicolumn{6}{|c|}{ Partner Employment Status } \\
\hline Unemployed & 1.4 & 3.4 & 5.8 & 6.8 & 3.6 \\
\hline Employed & 95.8 & 94.8 & 91.8 & 91.1 & 94.0 \\
\hline Don't Know & 2.8 & 1.8 & 2.4 & 2.1 & 2.3 \\
\hline \multicolumn{6}{|l|}{ Partner Education } \\
\hline No Education & 64.9 & 31.8 & 9.7 & 8.6 & 37.7 \\
\hline Primary & 13.4 & 19.2 & 53.2 & 53.6 & 28.0 \\
\hline Secondary & 18.5 & 41.0 & 30.8 & 33.9 & 29.4 \\
\hline Higher & 2.3 & 3.2 & 6.2 & 0.9 & 2.4 \\
\hline Don't Know & 1.0 & 4.9 & 0.0 & 3.0 & 2.5 \\
\hline
\end{tabular}


Table 2: Implications of child marriage on reproductive health and infant mortality, (DHS 2010-15)

$\begin{array}{llll}\text { West Africa } & \text { Central Africa } & \text { East Africa } & \text { Southern Africa }\end{array}$

\section{MODERN CONTRACEPTIVE USE - Odds Ratio [Confidence Interval]}

\begin{tabular}{|c|c|c|c|c|c|}
\hline Child $(<18)$ at Marriage & $1.08[0.935-1.243]$ & $0.84[0.710-1.005]$ & $0.90[0.781-1.047]$ & $1.32 *[1.198-1.464]$ & $0.92 *[0.869-0.982]$ \\
\hline Adult $(\geq 18)$ at Marriage & Reference & Reference & Reference & Reference & Reference \\
\hline \multicolumn{6}{|c|}{ SEXUAL VIOLENCE - Odds Ratio [Confidence Interval] } \\
\hline Child $(<18)$ at Marriage & $1.15[0.895-1.485]$ & $1.30 *[1.049-1.608]$ & $1.57 *[1.119-2.205]$ & $1.26 *[1.046-1.510]$ & $1.33 *[1.188-1.487]$ \\
\hline Adult $(\geq 18)$ at Marriage & Reference & Reference & Reference & Reference & Reference \\
\hline \multicolumn{6}{|c|}{ NUMBER OF ANTENATAL CARE VISIT - Incidence Rate Ratio [Confidence Interval] } \\
\hline Child $(<18)$ at Marriage & $0.89 *[0.875-0.913]$ & $0.94 *[0.912-0.967]$ & $0.98[0.946-1.021]$ & $0.99[0.962-1.012]$ & $0.94 *[0.926-0.950]$ \\
\hline Adult $(\geq 18)$ at Marriage & Reference & Reference & Reference & Reference & Reference \\
\hline \multicolumn{6}{|c|}{ HEALTH PLACE OF DELIVERY - Odds Ratio [Confidence Interval] } \\
\hline Child $(<18)$ at Marriage & $0.48 *[0.432-0.530]$ & $0.54 *[0.468-0.621]$ & $0.56 *[0.466-0.665]$ & $0.7 \mid *[0.628-0.806]$ & $0.53 *[0.495-0.560]$ \\
\hline Adult $(\geq \mid 8)$ at Marriage & Reference & Reference & Reference & Reference & Reference \\
\hline \multicolumn{6}{|c|}{ SKILLED BIRTH ATTENDANT - Odds Ratio [Confidence Interval] } \\
\hline Child $(<18)$ at Marriage & $0.66 *[0.591-0.726]$ & $0.68^{*}[0.597-0.775]$ & $0.57^{*}[0.482-0.674]$ & $0.78 *[0.704-0.875]$ & $0.65 *[0.609-0.685]$ \\
\hline Adult $(\geq \mid 8)$ at Marriage & Reference & Reference & Reference & Reference & Reference \\
\hline \multicolumn{6}{|c|}{ INFANT SURVIVAL - Hazard Ratio [Confidence Interval] } \\
\hline Child $(<18)$ at Marriage & $0.82 *[0.772-0.864]$ & $0.84^{*}[0.788-0.906]$ & $0.84 *[0.761-0.925]$ & $0.87^{*}[0.819-0.924]$ & $0.84^{*}[0.8 \mid 4-0.869]$ \\
\hline Adult $(\geq 18)$ at Marriage & Reference & Reference & Reference & Reference & Reference \\
\hline
\end{tabular}

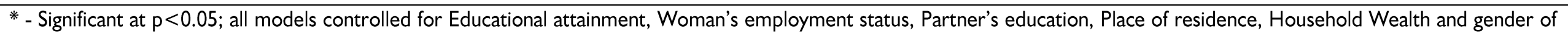
household head. Place of delivery, skilled birth attendant, birth type and Child sex were added as covariates for infant survival model. 
Relationship between child marriage and sexual health of adolescents in sub-Saharan Africa and sub-regions

Results of the logistic regression presented in the Table 2 above show that women that married as a child in sub-Saharan Africa were [OR:0.92, Cl: 0.869

- 0.982] less likely to use a modern method of contraception compared to those that married as adults. Surprisingly, the results also show that those who married as children in the Southern Africa region were about 32\% [OR:I.32, Cl:I.198 - 1.464] more likely to use a modern method of contraception compared to those that married as adults. Similarly, women who married as a child in sub-Saharan Africa were significantly more [OR:I.33, Cl:I.I88 - I.487] likely to experience sexual violence compared to those who married as an adult. Examining this relationship across the sub-regions, women who married as children were also significantly more likely to experience sexual violence in Central Africa [OR:I.30, Cl: 1.049 - I.608, East Africa [OR:I.57, Cl:I.II -2.205 ] and Southern Africa [OR:I.26, Cl:I.046-I.5I0] all compared to women who were married as adults. Across countries, results from figure 3 show that in five of the countries (Gambia, Kenya, Malawi, Zimbabwe) women who married as a child were significantly more likely to use a modern method of contraception compared to those that married as adults. In countries (Cameroon, Chad, Republic of Congo, Sierra Leone) where the likelihood was lower, we found no significant association between modern contraceptive usage and child marriage. 
Figure 3: Relationship between child marriage and modern contraceptive in sub-Saharan Africa Countries

SSA

Southern Africa

Malawi

Mozambique

Namibia

Zambia

Zimbabwe

East Africa

Comoros

Kenya

Rwanda

Uganda

Central Africa

Congo DR

Cameroon

Chad

Gabon

West Africa

Burkina Faso

Gambia

Nigeria

Sierra Leone

Togo

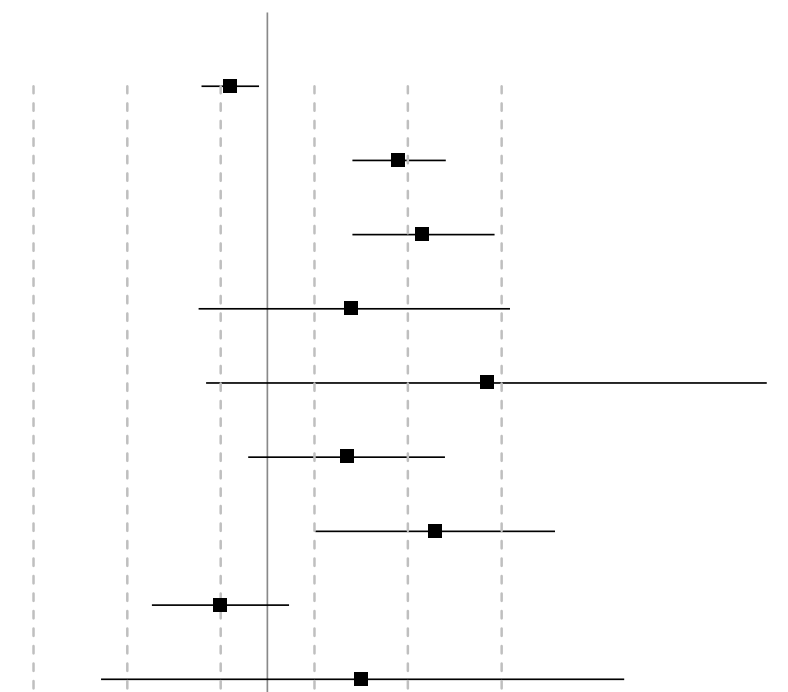

Coeff $[95 \% \mathrm{Cl}]$

$-0.08[-0.14 \mid,-$

$0.018]$

$0.28[0.18 \mathrm{I}, 0.38 \mathrm{I}]$

$0.33[0.181,0.485]$

$0.18[-0.147,0.5 \mid 8]$

$0.47[-0.131,1.066]$

$0.17[-0.04 I, 0.379]$

$0.36[0.102,0.6 \mid 4]$

$-0.1[-0.247,0.046]$

$0.2[-0.356,0.762]$

$0.39[0.142,0.64]$

$0.14[-0.239,0.52]$

$0.3[-0.034,0.634]$

$-0.24[-0.56,0.074]$

$-0.19[-0.467,0.09]$

$-0.16[-0.683,0.373]$

$-0.16[-0.683,0.373]$

$0.18[-0.228,0.594]$

$0.08[-0.067,0.218]$

$0.2[-0.04 I, 0.439]$

$0.69[0.155,1.226]$

$0.1[-0.181,0.389]$

$-0.09[-0.426,0.253]$

$0.28[-0.12,0.672]$

$\begin{array}{llllll}-1.00 & -0.50 & 0.00 & 0.50 & 1.00 & 1.50\end{array}$

Higher Likelihood

\section{Lower Likelihood}

Similarly, examining the risk of sexual violence across the countries as evident in figure 4, we observed that marrying young women that married as a child in 13 of the studies countries were more likely to experience sexual violence but the relationship was only significant in four countries (Cameroon, Republic of Congo, Sierra Leone, Uganda).
Relationship between child marriage and the reproductive health of young women in subSaharan Africa and sub-regions

Results from table 2 also showed that women who married as a child have fewer antenatal visits in subSaharan Africa [0.92, Cl:0.910-0.935] and sub-regions including West Africa [OR:0.89, 0.868-0.906], Central Africa [OR:0.94, Cl:0.9/3-0.968], East Africa [OR:0.98, Cl: 0.940-I.016] and Southern Africa [OR:0.92, Cl:0.910-0.935]. Similarly, we found that 
women who were married as a child in sub-Saharan Africa were significantly less likely [OR:0.65, 0.6080.690 ] to be assisted by a skilled doctor, nurse or midwife during delivery compared to women who married as an adult. The same pattern can be observed in West Africa [OR:0.70, Cl:0.625-0.779], East Africa [OR:0.59, Cl:0.508-0.680], Central Africa [OR:0.65, Cl:0.534-0.789] and Southern Africa regions [OR:0.80, Cl:0.7I 7-0.898].

Figure 4: Relationship between child marriage and sexual violence in sub-Saharan Africa Countries

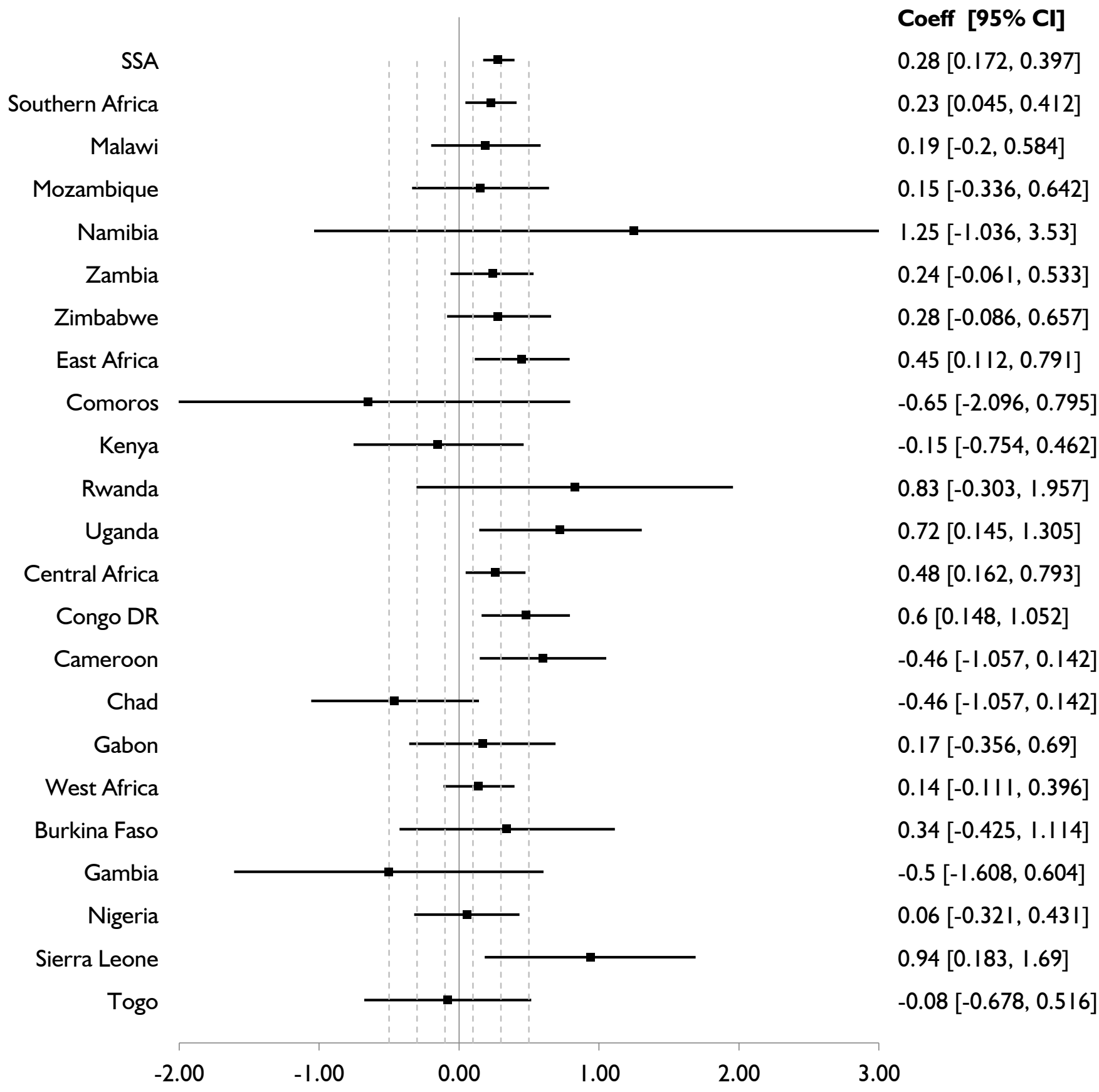

Lower Likelihood

$(<0)$

Higher Likelihood (>0) 
Figure 5: Relationship between child marriage and number of antenatal attendance in sub-Saharan Africa Countries

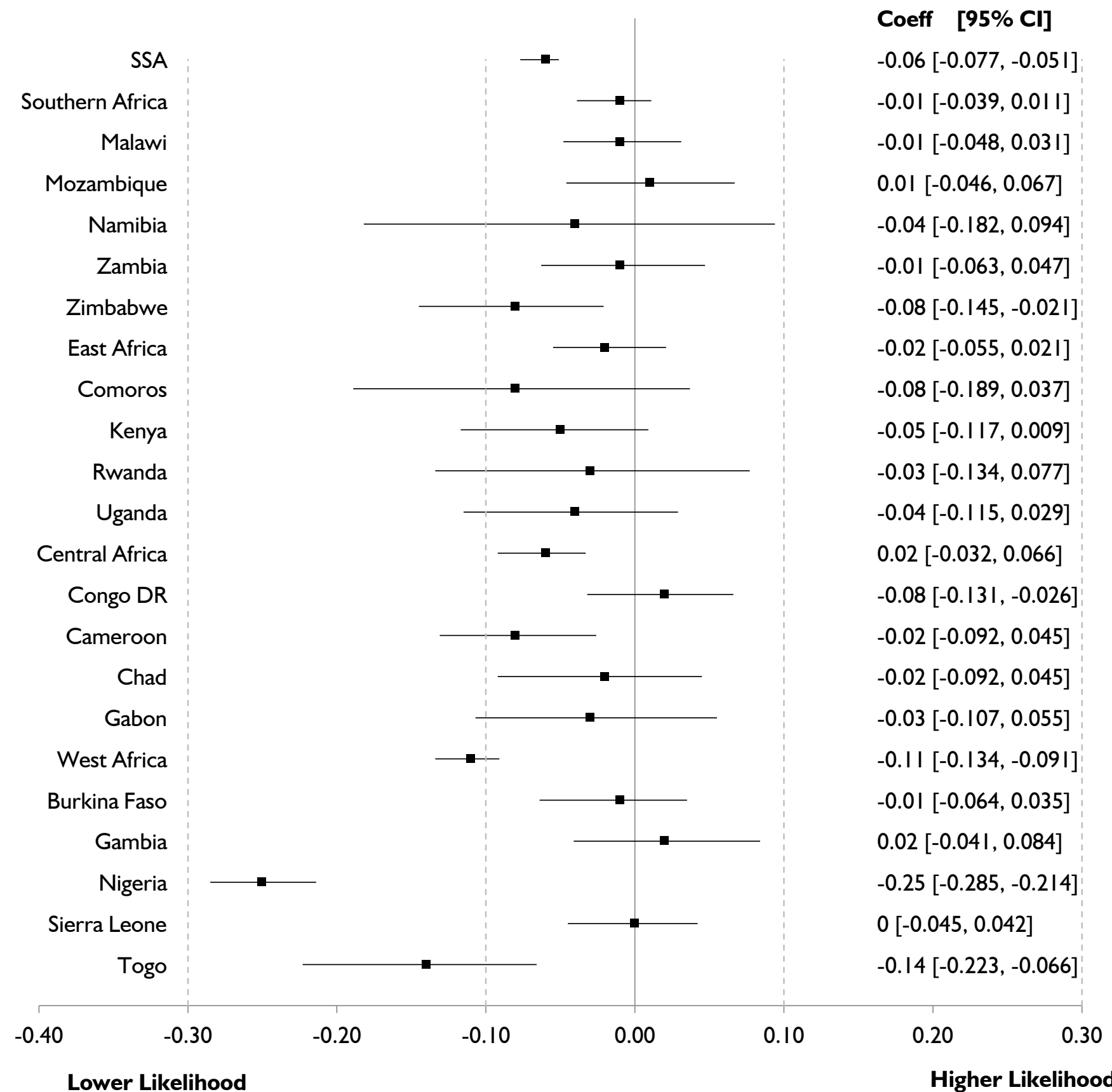

Similarly, women who married as a child in subSaharan Africa were also about 45\% [OR:0.55, $\mathrm{Cl}: 0.5 \mid 4-0.58 \mathrm{I}]$ less likely to deliver at a health facility compared to women who married as adults. Results from figure 5 also show that in almost (14) all the countries, adolescents who married as a child had lower antenatal care visits for their first births compared to those who married as adults although the relationship was only statistically significant in Cameroon, Nigeria, Togo, Zimbabwe.

In Sierra Leone, however, there was no difference in the number of antenatal visits among adolescents that married as a child compared to those who married as adults. Consequently, from figure 6 we found more evidence in about 16 countries that child brides compared to those who married as adults were less likely to be assisted by a skilled birth attendant but the relationship is only significant in seven countries (Cameroon, Chad, Gambia, Malawi Nigeria, Zambia, Zimbabwe). In relation to place of delivery as evident in figure 7, marrying as a child in Burkina Faso, Cameroon, Chad, Gambia, Malawi, Nigeria, Togo, Zambia, Zimbabwe, was significantly associated with a lower likelihood of delivering a first birth at a health facility compared to marrying as an adult. 
Figure 6: Relationship between child marriage and skilled birth in sub-Saharan Africa Countries

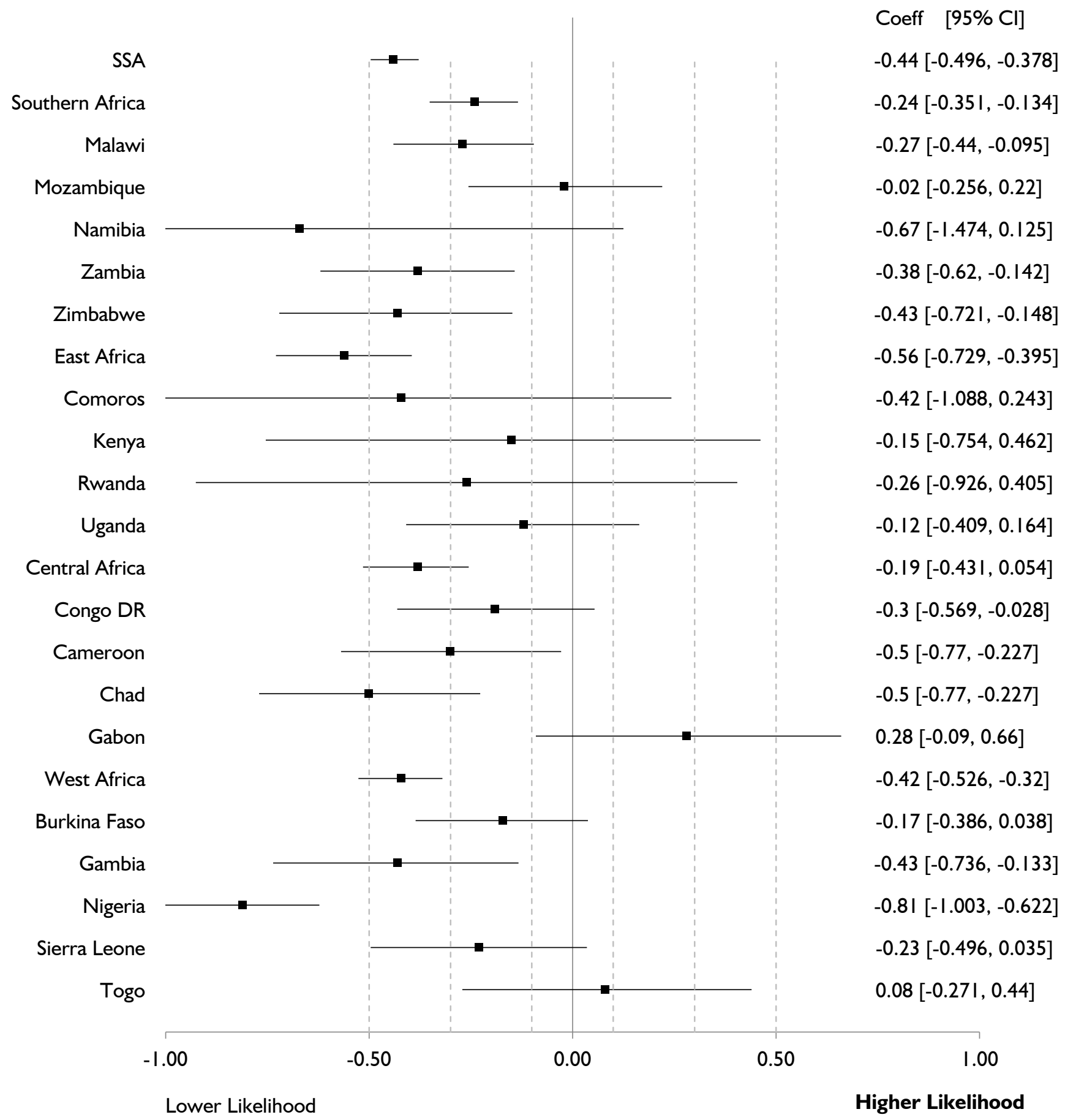


Figure 7: Relationship between child marriage and place of delivery in sub-Saharan Africa Countries

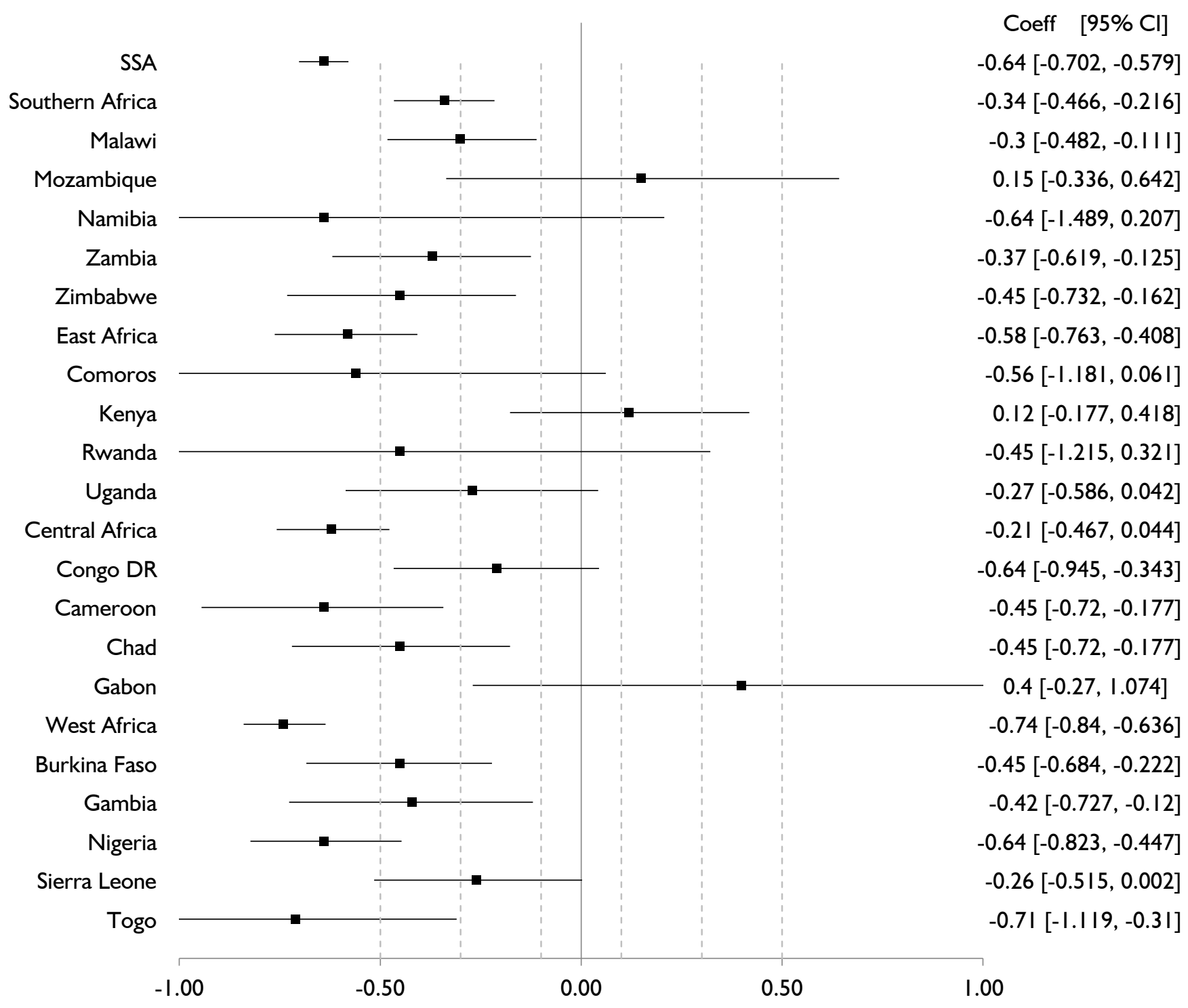

Lower Likelihood

Higher Likelihood 
Figure 8: Relationship between child marriage and infant survival in sub-Saharan Africa Countries

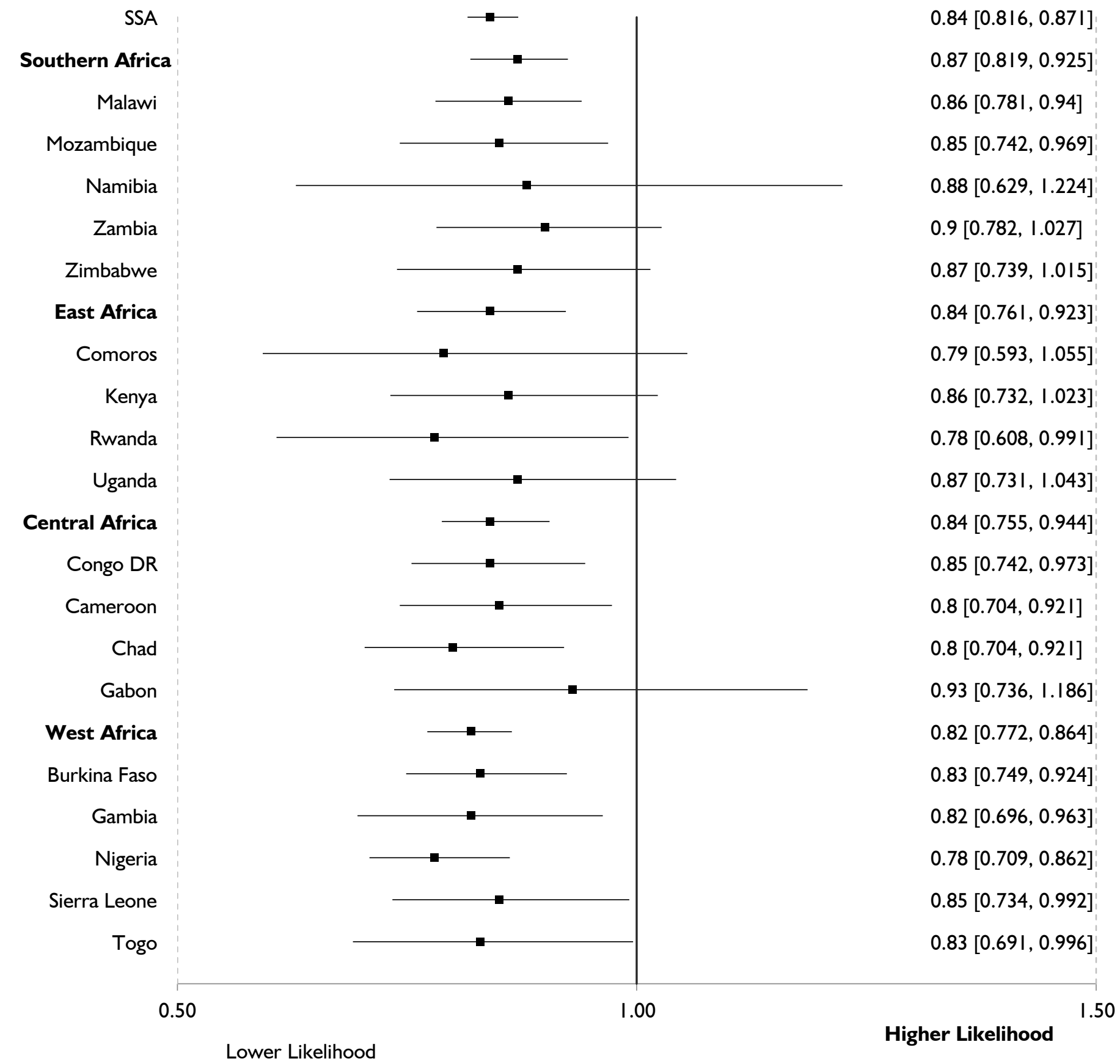

Relationship between child marriage and infant survival of adolescents in sub-Saharan Africa and sub-regions

In relation to infant survival, we found that women who were married as a child had a significantly lower likelihood of having their first child survive infancy in West Africa [HR:0.82, Cl: 0.772 - 0.864], Central Africa [HR:0.84, Cl:0.788 - 0.906], East Africa [HR: 0.84, Cl: $0.761-0.925]$, Southern Africa [HR:0.87,Cl: $0.819-0.924]$ and sub-Saharan Africa [HR:0.84,
$\mathrm{Cl}: 0.814-0.869]$ compared to women who married as an adult. As presented in figure 8 , we found that marrying as a child was associated with a lower likelihood of infant survival in all the countries. Results suggest that first births of women that married as a child were significantly less likely to survive infancy in 10 of the studied countries (Burkina Faso, Cameroon, Chad, Gambia, Malawi, Mozambique, Nigeria, Republic of Congo, Rwanda, Sierra Leone, Togo) compared to those that married as an adult. 


\section{Discussion}

Findings from this study highlight the prevalence of child marriage in sub-Saharan Africa (13\%) and across its sub-regions with regional variations above one-tenth in most of the regions. Indications are also that about half or majority of the married girls in West Africa, East Africa, and sub-Saharan Africa only had sex at their first union. Although the majority are yet to give birth, more than one-third of the girls have already given birth in all the regions. Exploring the implications of child marriage for infant survival, sexual and reproductive health, this study hypothesized that women that marry as a child were likely to suffer negative sexual and reproductive health and a lower likelihood of survival for their infants. This is based on the premise that women that marry as children may lack the necessary knowledge and skills that may be beneficial for their health and that of their infants.

Emerging findings from this study were consistent as hypothesized with a higher likelihood of experiencing negative sexual and reproductive health and higher hazards of infant mortality among children of child brides compared with those of adult mothers in most of the sub-regions including sub-Saharan Africa. Despite the family support in child marriage, findings from this study were consistent with other studies where higher rates of girl child marriage were significantly linked with higher rates of infant mortality and non-utilization of maternal health services (Raj \& Boehmer, 2013; Santhya, 20II; Santhya, et al., 2010). This may in part be because the child brides often have lower levels of education compared to women who married as adults and are more likely to be living in poor households with limited access to health care facilities (Santhya \& Jejeebhoy, 2003). Lower likelihood of infant survival among children of child brides is also likely to be because child brides are likely to be assisted by an unskilled birth attendant and deliver at a non-health facility both of which are characterized by a lack of facilities necessary for a safe delivery (Hossain \& Mondal, 2009). Furthermore, the finding that childbrides are likely to experience sexual violence is supported by a research in Ethiopia where adolescents who marry earlier were at a higher risk of intimate partner violence compared to those who married later (Erulkar, 2013). This finding is also consistent with other studies of women in India where marriage before age eighteen was associated with the experience of intimate partner violence (Speizer \& Pearson, 20I I; Joshi, et al., 200I).

This study suggests that women that marry as children were more likely to use a modern method of contraception compared to women who marry as adults. Although surprising, this study found coherence with a study of women in India and Bangladesh, where women who married as children were more likely to be using a modern method of contraception than those who had married as adults (Godha, Hotchkiss \& Gage, 2013). It is also likely that women in our sample who married before age 18 years had completed their desired family size by the time of the survey especially since they were exposed to childbearing at an early age (Godha, Hotchkiss \& Gage, 2013).

There are several strengths to these findings. The first is that these data come from a well-defined geographical area using standard and structured questionnaires which are representative of childbrides and first births of currently married women in sub-Saharan Africa. This has allowed for a direct comparison and has greatly increased our chance of accurately estimating the implications of child marriage for sexual and reproductive health and the hazards of dying in infancy across sub-Saharan Africa and its sub-regions. The second is the relatively large sample size which increases the statistical power of this study to detect differences and allow for important sensitivity analyses. There are, however, limitations to these findings. First, the child-bride sample for descriptive analysis was limited to only girls who were married between ages 15-17 years although it is not expected that there will be more married girls younger than age 15 years. This was, however, dealt with in the regression analysis by examining age at first marriage among women aged 20-24 years to account for marriages below age 15 years.

\section{Conclusion and recommendations}

In conclusion, findings from this study highlights that child marriages are to some extent not only high in Asian countries but also in sub-Saharan Africa and most of its sub-regions. Findings also showed that child brides are often married as virgins in most of the sub-regions with many residing in a rural place of residence, poor households, mostly having primary education, many of whom are also married to older men who also have less than secondary education. It was also observed that child marriage has negative implications for the sexual and reproductive health of the child brides as well as the survival of their infants. There is therefore, an urgent need to address this family formation type because of its serious negative implications for the girls, their children and families as well as the society at large. These may be to strengthen policies and programmes aimed at providing easy access to education that may keep girls longer in school or through incentives which may help discourage parents from giving out their daughters at such a tender age. 


\section{Acknowledgements}

Authors gratefully acknowledge the supports and comments from the 2016 Family Demography in African and Post-2015 Development Agenda Conference, hosted by Demography and Population Studies and co-sponsored by the NRF CoE in Human Development, NRF Conference Fund and National Institute for the Humanities and Social Sciences (NIHSS).

\section{Authors' contributions}

EO conceptualised the research, EO, and VC analysed the data and interpreated the results, all authors contributed to the writing of the manuscript, VC and JA contributed to critical revision of the intellectual content. All athours approved the final version to be published.

\section{References}

Alam, N. 2000. "Teenage motherhood and infant mortality in Bangladesh: maternal age-dependent effect of parity one." J Biosoc Sci., 32, 229-36.

Bruce, J. and Clark, S. 2003. "Including Married Adolescents in Adolescent Reproductive Health and HIV/AIDS Policy." Geneva: World Health Organization;

Daysal, N., Trandafir, M. and Van Ewijk, R. 2012. "Saving lives at birth: The impact of home births on infant outcomes." American Economic Journal: Applied Economics, 7, (3): 28-50.

Erulkar, A. 2013. "Early marriage, marital relations and intimate partner violence in Ethiopia." International Perspectives on Sexual and Reproductive Health, 6-I3.

Godha, D., Hotchkiss, D.R. and Gage, A.J. 2013. "Association between child marriage and reproductive health outcomes and service utilization: a multi-country study from South Asia." Journal of Adolescent Health, 52, (5): 552-558.

Hossain, K. and Mondal, N. 2009. "A Study on the Health Factors of Infant and Child Mortality in Rajshahi, Bangladesh.” Asian J Med Sci., I, (2): 8287.

Jejeebhoy, S.J. and Cook, R.J. 1997. "State accountability for wife-beating: the Indian challenge." The Lancet, 349, SI0-SI 2.

Joshi, A., Dhapola, M., Kurian, E. and Pelto, P.J. 2001. "Experiences and perceptions of marital sexual relationships among rural women in Gujarat, India." Asia-Pacific Population Journal, 16(2): 177194

International journal of epidemiology, 38, (2): 577585. Santhya, K.G. 20II. "Early marriage and sexual and reproductive health vulnerabilities of young women: a synthesis of recent evidence
Lee-Rife, S., Malhotra, A., Warner, A., and Glinski, A.M. 20I2. "What works to prevent child marriage: a review of the evidence." Studies in family planning, 43, (4): 287-303.

Mathur, S., Greene, M. and Malhotra, A. 2003. "Too Young to Wed: The Lives, Rights and Health of Young Married Girls." Washington, DC: International Center for Research on Women. I15.

Mondal, N. I., Hossain, K. and Ali, K. 2009. "Factors influencing infant and child mortality: A case study of Rajshahi District, Bangladesh." Journal of Human Ecology, 26, (I): 3I-39.

Nour, N.M. 2006. "Health Consequences of Child Marriage in Africa." Emerging Infectious Diseases 12, (I I): 1644-1649

Nour, N.M. 2009. "Child marriage: a silent health and human rights issue." Rev Obstet Gynecol, 2, (I): $5 \mathrm{I}-56$.

Paul, V.K., et al. 20II. "Reproductive health, and child health and nutrition in India: meeting the challenge." The Lancet, 377, (9762): 332-349.

Phipps, M., Sowers, M. and DeMonner, S. 2002. "The risk for infant mortality among adolescent childbearing groups.” J Womens Health. II, 88997.

Prakash, R., Singh, A., Pathak, P.K. and Parasuraman, S. 20II. "Early marriage, poor reproductive health status of mother and child well-being in India." Journal of family planning and reproductive health care, 37: I36- 145

Raj, A. 20I0. "When the mother is a child: the impact of child marriage on the health and human rights of girls." Archives of disease in childhood, 95: 931935.

Raj, A. and Boehmer, U. 20I3. "Girl child marriage and its association with national rates of HIV, maternal health, and infant mortality across 97 countries." Violence Against Women, 19, (4): 536551.

Raj, A., Saggurti, N., Winter, M., Labonte, A., Decker, M., Balaiah, D. and Silverman, J. 2010. "The effect of maternal child marriage on morbidity and mortality of children under 5 in India: cross sectional study of a nationally representative sample.” BMJ, 340: b4258

Rocca, C. H., Rathod, S., Falle, T., Pande, R.P and Krishnan, S. 2009. "Challenging assumptions about women's empowerment: social and economic resources and domestic violence among young married women in urban South India." from developing countries." Current opinion in obstetrics and gynaecology. 23, (5): 334-339.

Santhya, K. G., Ram, U., Acharya, R., Jejeebhoy, S.J., Ram, F. and Singh, A. 20I0. "Associations between early marriage and young women's 
marital and reproductive health outcomes: evidence from India." International perspectives on sexual and reproductive health. I32-139.

Santhya, K.G. and Jejeebhoy S.J. 2003. Sexual and reproductive health needs of married adolescent girls. Economic and Political Weekly. 37, (4I): 43704380.
Speizer, I.S. and Pearson, E. 20II. "Association between early marriage and intimate partner violence in India: a focus on youth from Bihar and Rajasthan." Journal of interpersonal violence. 26, (10): 1963$198 \mid$. 